\title{
Seismic performance evaluation of GLD beam-column sub-assemblages of three different scenarios
}

\author{
A KANCHANADEVI ${ }^{1,2, *}$, K RAMANJANEYULU $^{1,2}$, SAPTARSHI SASMAL $^{1,2}$ \\ and V SRINIVAS ${ }^{1,2}$ \\ ${ }^{1}$ CSIR-Structural Engineering Research Centre, Chennai 600113, India \\ ${ }^{2}$ Academy of Scientific and Innovative Research (AcSIR), Chennai, India \\ e-mail: kanchana@serc.res.in
}

MS received 16 February 2017; accepted 10 June 2018; published online 3 November 2018

\begin{abstract}
Gravity load designed (GLD) structures exhibit poor seismic performance due to inadequate reinforcement to cater for the seismic forces, lack of confinement, poor joint strength, improper anchorage, presence of weak column and strong beams. These structures are also susceptible to environmental impact leading to corrosion of reinforcement which would further degrade their seismic performance. In RC structures, beam-column joints are crucial members and dissipate the seismic energy imparted to the structure. Hence in this study, two typical cases of GLD (i) uncorroded GLD and (ii) corrosion affected GLD (corroded) exterior beam-column sub-assemblages subjected to reverse cyclic loading are investigated and compared. Reinforcement corrosion of one of the GLD specimens is accelerated by the impressed current technique. Based on the investigation on uncorroded GLD and corrosion affected GLD beam-column specimens, it is noted that the corrosion has significant effect on the seismic performance in terms of loss of energy dissipation, strength- and stiffness- degradation. To improve the seismic performance of uncorroded GLD specimens, a low invasive single steel haunch upgradation scheme (SHUS) is proposed in this study. The maximum load carried by steel haunch upgraded GLD specimen is about 30\% higher than that of GLD specimen. Hence, it is noted that by implementing the proposed upgradation scheme for GLD beam-column sub-assemblage, remarkable improvement in the seismic response can be achieved. The present study provides insight into the behaviour of steel haunch upgraded GLD specimen and would also pave the way for formulating seismic upgradation of even corroded GLD beam-column sub-assemblage.
\end{abstract}

Keywords. Corrosion; steel haunch upgradation scheme; energy dissipation; stiffness degradation; strength degradation.

\section{Introduction}

Before the introduction of modern seismic design philosophies, the structures were designed for gravity loads and these gravity load designed (GLD) structures exist all over the world even in the regions of high seismicity. The catastrophic collapse of existing structures during the past earthquake necessitated the seismic performance evaluation of these GLD structures. GLD structures have inherent weakness in the form of inadequate reinforcement to cater for seismic loading, existence of weak beam column and strong beam, lack of confinement in the disturbed regions of the beam-column sub-assemblage, inadequate joint strength, improper reinforcement detailing, etc. All these lead to the poor performance of these GLD structures during the past earthquakes. In reinforced concrete (RC) framed buildings,

*For correspondence beam-column joint is the most critical component as it incur huge shear demand compared to the adjacent beam and column. Hence, seismic performance evaluation of representative beam-column sub-assemblage is more appropriate for the seismic performance evaluation of $\mathrm{RC}$ framed structures. Numerous experimental investigations were carried out by researchers to understand the seismic behavior of GLD structures. Aycardi et al [1] studied the performance of Gravity Load Designed (GLD) sub-assemblages under seismic type of loading. Parameters like axial load level, withand without- lap splice were studied. Further, analytical model was developed to model the seismic behaviour and identify the parameters which play a key role under seismic loading. Bracci et al [2] conducted series of tests to evaluate the seismic resistance of three storied RC scaled GLD structural frames. It was observed that the GLD structures mainly suffered from strong beam-weak column. El-Attar et al [3] brought out the behaviour of GLD RC buildings 
(according to ACI 318) under seismic loading. It was found that even moderate earthquakes produced very large deformations associated with considerable stiffness degradation for GLD RC buildings without walls. Elwood and Moehle [4] investigated the collapse mechanism of gravity load designed RC frames by using shake table test to observe the process of failure due to dynamic shear and axial load. It was observed that the RC frame was characterized by low ductile columns with a predominant shear failure mode, which further accelerated the lateral strength degradation process. Further, it was reported that the axial load on the column influences the behavior of the column during shaking, particularly after shear failure. Dhakal et al [5] carried out an experimental study on dynamic response of GLD RC connections. It was observed that, though the connection zones are the most important parts in dissipating energy during an earthquake, most of the GLD connections are weaker than the adjoining structure and failed in shear. Ramanjaneyulu et al [6] evaluated the seismic performance of exterior beam-column sub-assemblages designed according to different stages of development of Eurocode (EC) and Indian Standard codes of practice. It was found that the gravity load designed (GLD) structure is vulnerable to even medium intensity earthquake. Among the seismically designed specimens without ductile detailing, the one which was designed as per IS codes was found to exhibit better performance with $10 \%$ more energy dissipation under large drift ratio compared to that designed according to the EC. Among the seismically designed and ductile detailed specimens, the one designed as per EC provisions for medium ductility could not perform as good as that designed according to ductile detailing provisions of IS Code.

Most of the existing RC framed structures are decades old and were exposed to aggressive corrosive environment. The presence of moisture and oxygen supply will induce corrosion of reinforcement in RC structures. Corrosion of reinforcement reduces the mechanical properties of the steel reinforcement, depletes the bond between steel and concrete and produce cracks in the surrounding concrete due to the expansive force produced during the corrosion of steel. Almusallam [7], Palsson and Mirza [8], Du et al [9], Shin et al [10], Cairns et al [11], and Apostolopoulos and Papadakis [12], Xia et al [13] examined the effect of corrosion on the mechanical properties of corroded reinforcing steel bars. The effect of corrosion on the bond degradation of RC members was studied by Fang et al [14], Bhargava et al [15], Chung et al [16] and Lee et al [17]. Lee et al [18] studied the behaviour of corrosion damaged RC columns under cyclic lateral loading and also, carried out retrofitting of the columns using carbon fiber sheets. It was reported that retrofitting improved the ductility and reduced the bond splitting cracks and shear cracks of the column. Almusallam et al [19] studied the flexural behaviour of slabs with different levels of reinforcement corrosion. It was observed that the corrosion of reinforcement reduces both strength and ductility of the slabs. Acosta et al [20] correlated flexure capacity loss of beams with steel crosssection loss due to uniform corrosion of reinforcement steel in humid environment. Most of the works reported on the effect of corrosion of reinforced concrete are confined to the component level understanding and further the efforts to understand the influence of seismic performance of the beam-column sub-assemblage are very scarce.

In view of poor performance of GLD beam-column joints of RC structures, lot of research was carried out on retrofit strategies for improved seismic performance of GLD structures. Different methods such as RC or steel plate jacketing, fiber reinforced polymers (FRP) as externally bonded reinforcement or wrapping, steel haunches, etc. were proposed for strengthening of the existing and damaged structures to resist seismic loading. Realfonzo et al [21] used various CFRP configuration schemes for strengthening and retrofitting of seismically deficient beam-column joints with different beam and column reinforcement ratios. It was reported that CFRP sheets used for strengthening of the joint region, may not improve the performance of the joint if they are not connected mechanically to the parent concrete. Further, they evaluated the performance of different configurations of CFRP in terms of different seismic performance parameters. It was reported that the strengthened specimens failed by delamination of FRP followed by the joint shear failure. Campione et al [22] used steel cages for strengthening of the exterior beam-column sub-assemblages and proposed a simplified analytical model that can be used for pushover analysis. The strengthening schemes were applied either only to the columns or to both columns and beams. The results obtained from their study highlighted the effectiveness of the external steel cage as strengthening system, which increases the flexural strength and facilitates to shift the failure mode from the column to the beam. Kalogeropoulos et al [23] used extension bars and steel plates and the RC jacketing of the columns and the joint region for the retrofitting of poorly detailed exterior $\mathrm{RC}$ beam-to-column joints. The experimental results revealed substantial improvement of the overall seismic behaviour of the retrofitted sub-assemblages compared to the control specimen. Yu et al [24] presented a seismic retrofit strategy for steel moment connections using haunches after the damages incurred by the welds during Northridge earthquake. Pampanin et al [25, 26] presented an innovative upgradation scheme for existing under-designed RC framed buildings using metallic haunches on both top and bottom faces of the beam and succeeded in redirecting the damage towards the beam. Genesio et al [27] used steel haunch type element with post-installed anchors for retrofitting of nonseismically detailed beam-column joints, in order to prevent brittle failure of the joint core. This method of retrofitting was found to be effective in safeguarding the joint region. However, providing double steel haunches interfere with the functionality of the buildings. Hence, there is a need for development of low invasive and practicable scheme. 
From the literature, it is clear that the GLD RC beamcolumn joints exhibited poor seismic performance due to their inherent weaknesses. Further, as these structures were built over decades ago, they manifested environmental degradation in the form of corrosion of reinforcement. Most of the studies on corrosion of reinforced concrete structures reported in the literature were focused on characterisation of effects of corrosion on the mechanical properties of steel reinforcement, bond behaviour of corroded reinforcement and few studies were reported on the flexural behaviour of corrosion affected beams, columns and slabs. No studies were reported on the behaviour of corrosion damaged RC beam-column sub-assemblages under reverse cyclic loading. Hence, in this study experimental investigations are carried out on corrosion affected GLD RC beam-column sub-assemblages to evaluate its effect on the seismic performance compared to that of the uncorroded GLD specimen. Leave alone the corrosion affected GLD beamcolumn sub-assemblage, there is an urgent need to devise low invasive upgradation scheme for improving the seismic performance of uncorroded GLD specimen. Hence, an attempt is also made in this study to devise a feasible low invasive upgradation scheme for GLD beam column subassemblage using single steel haunch upgradation scheme. On the whole, in the present study, seismic performance of beam-column sub-assemblage is evaluated for three cases namely, (i) uncorroded GLD beam-column sub-assemblage, (ii) corrosion damaged beam-column sub-assemblage, (iii) single haunch upgraded beam-column subassemblage.

\section{Details of gravity load designed (GLD) specimens of different scenarios for experimental investigations}

An exterior beam-column sub-assemblage of three storied, three bay, RC framed building with $6 \mathrm{~m}$ span and $3.5 \mathrm{~m}$ each floor height as shown in figure 1(a) is considered for the study. The building is analysed and designed for combination of dead load and live load according to Indian Standard codes of practice. An exterior beam-column specimen as shown in figure 1(b) is identified for design and for carrying out experimental investigations. The cross sectional dimensions of $300 \mathrm{~mm} \times 400 \mathrm{~mm}$ and $300 \mathrm{~mm} \times 300 \mathrm{~mm}$ are arrived for beam and column, respectively. The beams are designed for critical bending moment and shear force. The columns are designed for critical axial load and bending moment.

\subsection{Details of uncorroded GLD specimen SP1}

The reinforcement details of GLD specimen SP1 are shown in figure 1(c). The reinforcements at critical locations are instrumented with strain gages. The length of the beam is adopted as $1.7 \mathrm{~m}$. The lengths of the top and bottom segments of column are arrived based on the proportion of moments at the joint and are found to be $0.950 \mathrm{~m}$ and $2.450 \mathrm{~m}$, respectively. The detailed discussion on proportioning of members are found elsewhere Ramanjaneyulu et al [6]. Mix proportion of 1 (cement): 2.25 (fine aggregate): 2.35 (coarse aggregate $60 \%$ is of $10 \mathrm{~mm}$ size, $40 \%$ is of $20 \mathrm{~mm}$ size): 0.5 (w/c): $0.4 \%$ (super plasticizer) was adopted for casting of the specimens. The specimens were moist cured for a period of 28 days. The average compressive strength of concrete cubes is found to be $36.17 \mathrm{~N} / \mathrm{mm}^{2}$. The average yield strengths of reinforcement steel bars of $8 \mathrm{~mm}$, $16 \mathrm{~mm}$ and $25 \mathrm{~mm}$ diameter are found to be $406 \mathrm{~N} / \mathrm{mm}^{2}$, $496 \mathrm{~N} / \mathrm{mm}^{2}$ and $535 \mathrm{~N} / \mathrm{mm}^{2}$, respectively.

\subsection{Details of the corrosion damaged GLD specimen SP1-CR}

In the present study, deterioration of GLD beam-column sub-assemblage due to corrosion of reinforcement is considered. As the process of natural corrosion is very slow, corrosion of reinforcement in specimen SP1-CR is carried out by means of accelerated corrosion using impressed current technique. Insulated copper wires are soldered to the top and bottom main reinforcement bars of the beam for impressing current through the reinforcement. The insulated copper wires are routed through plastic sleeves for protecting them during casting. Steel being a good conductor of electricity, stirrups which are in contact with the main reinforcement will also get corroded and the extent of corrosion is function of concrete resistance. In the present study, the beam and adjoining joint region are immersed in $3.5 \% \mathrm{NaCl}$ solution as shown in figure 2. The schematic diagram of accelerated corrosion set-up for beam-column sub-assemblage is shown in figure 2. A cylindrical drum with slit opening is provided around the beam. The drum is supported at the bottom and sides by means of sand bags. The cathodic plates are inserted into the drum. The drum is sealed at the face of the joint using sealant. For the joint portion, plastic tray of suitable size is cut and sealed with sealant. Electrolyte is poured into the cylindrical drum through the slit opening. Stainless steel plate is used as cathodic plate and connected to the negative terminal of the DC pack. The beam main reinforcements (at both top and bottom) are connected to the positive terminal of the DC pack thereby acting as anode. Constant total impressed current of $5 \mathrm{~A}$ is applied to the reinforcement bars and a voltage of $11.6 \mathrm{~V}$ is recorded on the DC Pack. Oxidation or material loss or corrosion occurs at anode as given in Eq. (1).

$$
F e \rightarrow F e^{2+}+2 e^{-}
$$

The cathodic reaction is given by Eq. (2).

$$
2 \mathrm{H}_{2} \mathrm{O}+\mathrm{O}_{2}+4 e^{-} \rightarrow 4 \mathrm{OH}^{-}
$$



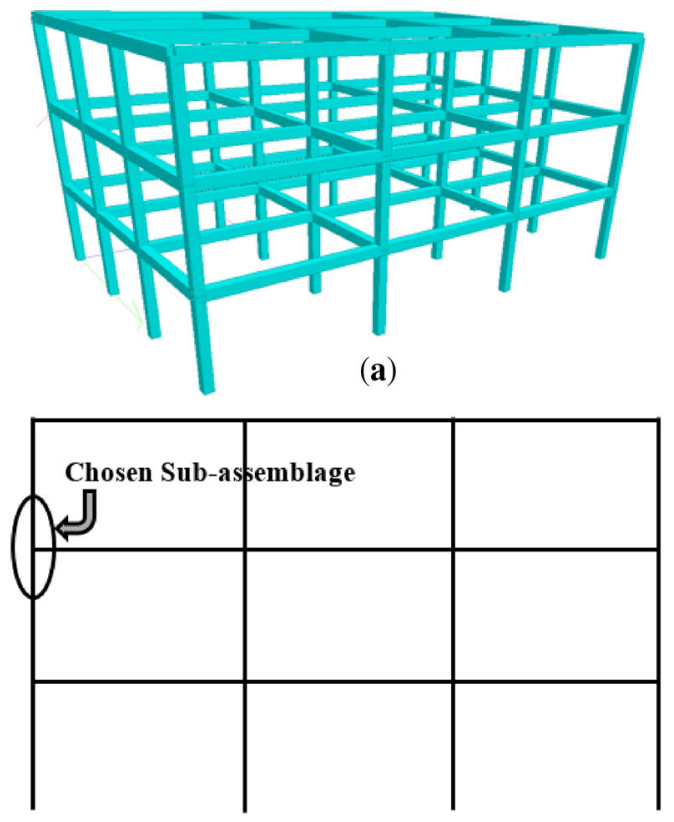

(b)

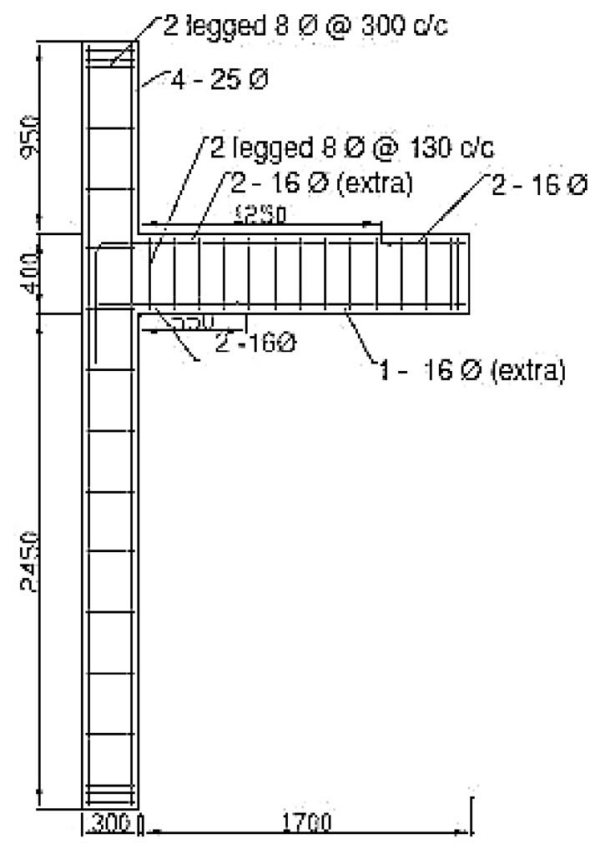

(c)

Figure 1. (a) Building chosen for study. (b) Chosen typical exterior beam-column sub-assemblage. (c) Reinforcement details of exterior beam-column sub-assemblage chosen.

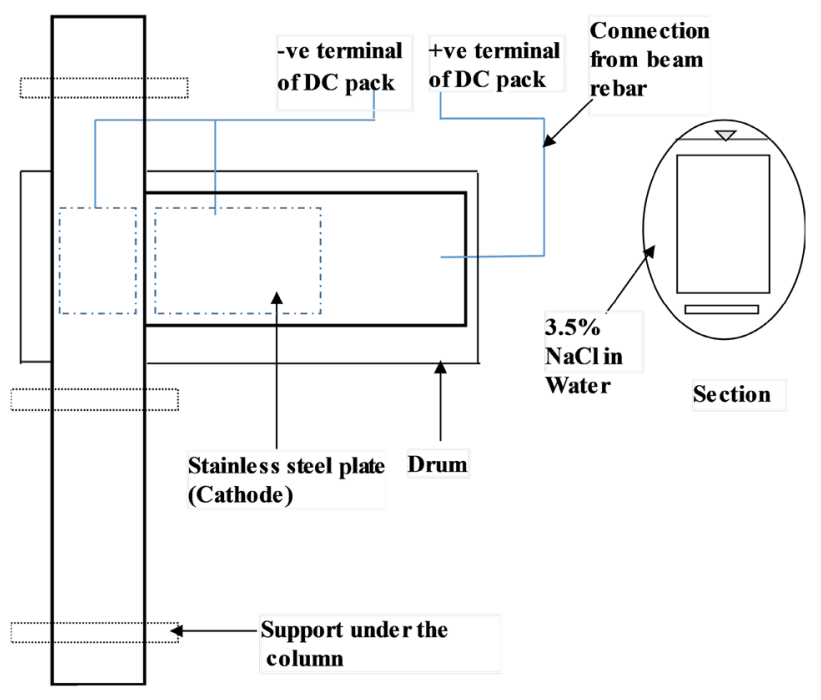

Figure 2. Schematic diagram of accelerated corrosion set-up.

The ferrous ion further reacts with the hydroxyl ion and forms various oxides of iron. In natural corrosion, part of the steel acts as cathode and the remaining part acts as anode. Whereas in accelerated corrosion using impressed current, the reinforcement as a whole is made as anode.

The specimen is subjected to accelerated corrosion for a period of 7 days until visible cracks are appeared on the surface of the concrete. The corrosion level in the reinforcement is estimated by gravimetric weight loss method after testing of specimen.

2.2a Measurement of level of corrosion: The level of corrosion in the reinforcement is evaluated by gravimetric weight loss measurement. After the completion of the cyclic test of the beam-column sub-assemblages, reinforcements of the specimen are extricated by removing the surrounding concrete. Corrosion was observed on beam main reinforcement bars, on the stirrups of the beam and column in the joint region. The extricated reinforcement rebars were cleaned by removing the concrete laitance using wire brush. Higher degree of corrosion was observed on the beam bottom reinforcements compared to that of the top reinforcements. It was also observed that almost the entire length of the stirrups was severely affected due to corrosion. The corroded portion of top, bottom reinforcement and stirrups were further cleaned using acid solution prepared by mixing $1000 \mathrm{ml}$ hydrochloric acid $(\mathrm{HCl}$, specific gravity 1.19), $20 \mathrm{~g}$ Antimony trioxide $\left(\mathrm{Sb}_{2} \mathrm{O}_{3}\right)$ and $50 \mathrm{~g}$ Stannous chloride $\left(\mathrm{SnCl}_{2}\right)$. The reinforcement bars were immersed in the solution for a period of $25 \mathrm{~min}$. After that, immersed rebars were taken out of the solution and washed with plain water and brushed gently to remove left outs. The cleaned reinforcements are weighed using the weighing balance with least count of $1 \mathrm{~g}$. From the measured weights before and after corrosion process, percentage weight loss due to corrosion is calculated. It is found that the maximum percentage weight loss due to corrosion in the beam top, bottom main reinforcement, and stirrups is $2.10 \%, 5.37 \%$ and $4 \%$, respectively. 


\subsection{Details of the upgraded GLD specimen SPI-U}

In this study, GLD specimen is upgraded by providing single haunch between the bottom face of the beam and side face of the column. As this haunch is provided only at the bottom of the beam, the retrofit will not cause hindrance to the occupants of the building. Even though providing single haunch is less effective compared to double haunch scheme, single haunch is selected in view of its low invasiveness and feasibility. By introducing the steel haunch element at a distance $L^{\prime}$ from the beam-column joint panel and connected at an angle to the beam, the following can be achieved. (i) Internal force transfer mechanism of the beam-column sub-assembly will significantly be altered, and (ii) the presence of haunch can significantly reduce the beam and column moments near the joint zone. The efficiency of the steel haunch is primarily dependent on the three design parameters, namely, the length of haunch, angle of steel haunch with the horizontal and the axial stiffness of the haunch. Figures 3(a) and (b) depict the effects of the haunch retrofit solution on moment clearly showing the reduction of moment due to implementation of haunch. Figures 3(c) and (d) depict the effect of haunch retrofit in reducing the shear force in joint region of an exterior beam-column sub-assembly subjected to lateral loads.

In the present study, the steel haunch of $30 \mathrm{~mm}$ diameter plain steel rod is welded at both of its ends to square bearing plate each of $300 \mathrm{~mm} \times 300 \mathrm{~mm} \times 12 \mathrm{~mm}$. The rod is stiffened by means of the triangular stiffener plate of $150 \mathrm{~mm} \times 150 \mathrm{~mm} \times 6 \mathrm{~mm}$ at both ends of the rod as shown in figure 4(a). The size of the rod, i.e., diameter, is arrived based on the maximum beam shear corresponding to GLD specimen. The bearing plates are connected to the faces of beam and column using anchor bolts as detailed in figure 4(b). The bearing plates are positioned at a distance of $400 \mathrm{~mm}$ from the face of the joint to the centre of the plate.

\section{Experimental investigations on GLD specimens of different scenarios}

The test set-up was arranged so that the beam-column joint can be tested horizontally. Positioning of specimen in the test set-up along with details of instrumentation scheme adopted for measurement of displacement is shown in figure 5. The reinforcements of the test specimen were instrumented by affixing strain gages at identified locations to measure the strain during progression of loading cycles. LVDTs were positioned at critical locations of beam and column portions of the sub-assemblage to measure deformations. An axial load of $300 \mathrm{kN}$ is applied to the column by a hydraulic jack at one end of the column against the reaction block at the other end. The level of axial load on the column was arrived through analysis of the global system of the three storey, three bay building. The axial load was kept constant during the test. The lateral load was applied at the beam tip in displacement control mode using $25 \mathrm{t}$ actuator, according to the loading history shown in figure 6. Reverse cyclic load is applied in terms of drift ratio $(\%)$ of the component where the drift is calculated according to Eq. (3)

$$
\text { Drift ratio }(\%)=\left(\Delta l / l_{b}\right) \text {. }
$$

where, $\Delta l$ and $l_{b}$ are the applied displacement at the beam tip and the length of the beam from column face to the application point of the displacement, respectively. The lateral displacement increments have been applied in a quasi-static reverse cyclic manner. Three complete cycles are applied for each drift ratio.

\section{Comparative performance of GLD specimens of different scenarios under reverse cyclic loading}

The specimens for three different scenarios of GLD beamcolumn sub-assemblage viz., uncorroded GLD specimen (SP1), corrosion damaged GLD specimen (SP1-CR), Upgraded uncorroded GLD specimen (SP1-U) are experimentally investigated under reverse cyclic loading. The drift ratios are applied as displacement at the tip of the beam in the displacement control mode. Comparative performance of these specimens is detailed in the following sections.

\subsection{Progression of cracking}

In specimen SP1, flexural cracks are developed at both top and bottom faces of the beam during initial drift cycles. Flexural cracks are developed at the beam bottom in SP1 during upward loading as shown in the figure 7a (Left). Upon further loading on specimen SP1, the shear cracks at the joint widened and wedging of concrete occurred at the joint region during negative cycles. A huge prominent crack along the joint line is observed at the failure stage [figure 7a (Right)] during positive cycle of loading. In specimen SP1-CR, flexure cracks similar to SP1 are found to have developed at the initial stage of loading [figure $7 \mathrm{~b}$ (Left)]. With further loading, shear cracks developed in the joint region and propagated along the top and bottom portions of the column during negative cycle. The prominent joint cracks formed are wider than that observed in the case of SP1 [figure 7b (Right)] during positive cycle of loading. At final stage of loading, integrity of concrete was completely lost and spalling of the cover concrete from the inner faces of the column adjacent to the joint was observed. Expansive forces exerted by the corrosion products damaged the surrounding concrete, which resulted in excessive spalling of cover concrete. In specimen SP1-U, 


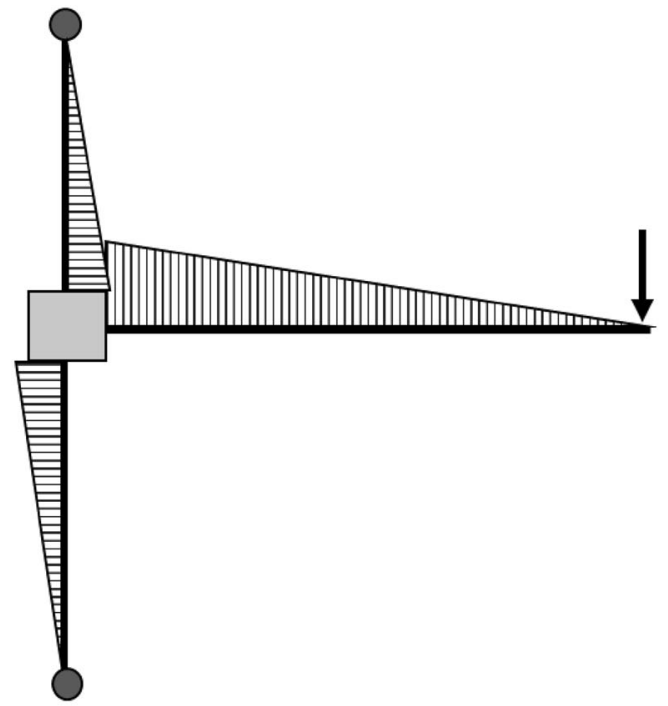

(a)

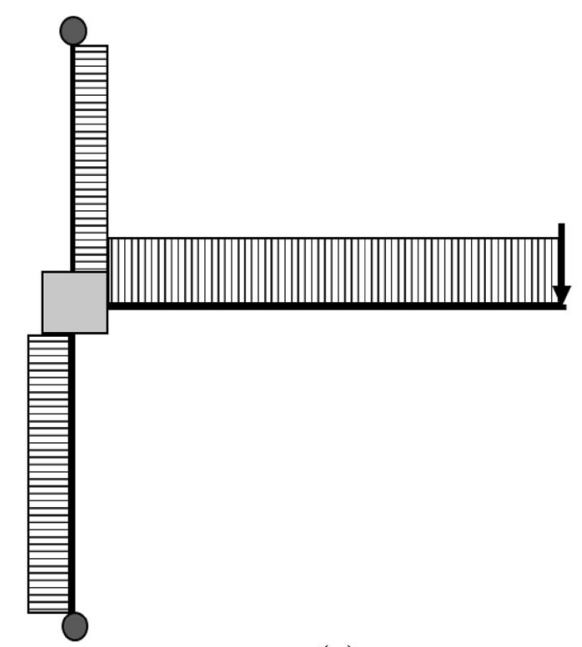

(c)

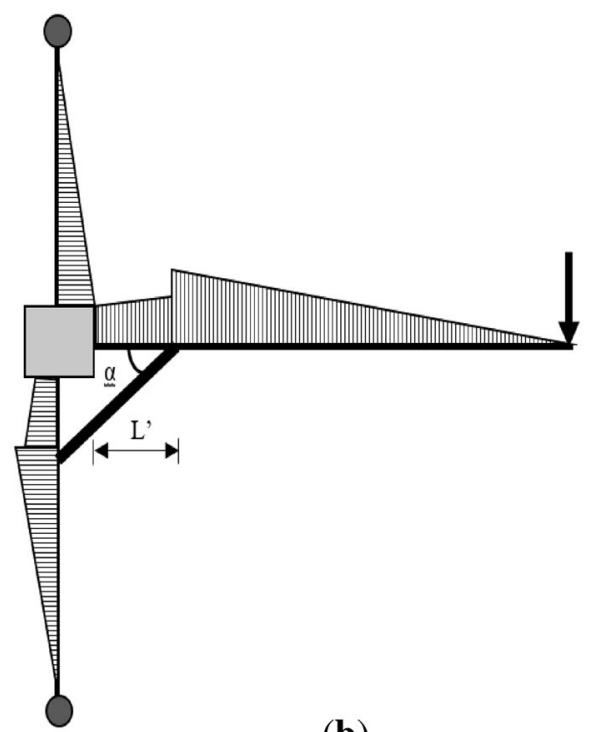

(b)

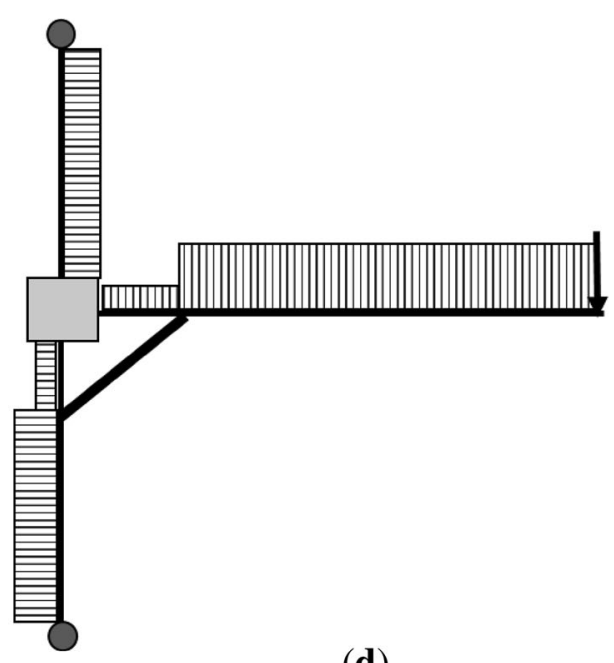

(d)

Figure 3. (a) Bending moment profile without haunch. (b) Bending moment profile with single haunch retrofit. (c) Shear force diagram without haunch. (d) Shear force diagram with single haunch retrofit.

flexural cracks are developed on either side of haunchbeam connection during positive cycle of loading. In this specimen, flexural cracks are developed along the length of the beam during initial stages of loading in both positive and negative cycles. Upon further loading, flexural cracking in the beam has been initiated along with hair-line shear cracks in the joint region [figure 7c (Left)]. With the further increase in load, haunch came into force and contributed significantly for enhancing the load carrying capacity of the beam-column sub-assemblage. As a consequence of haunch retrofit, most of the flexural cracks were found to be beyond the haunch connection point with the beam during positive cycle. At final stage of loading in SP1-U1, the damage happened in the form of joint shear cracks along both the diagonals of the joint forming diagonal struts [figure 7c (Right)]. In the case of upgraded specimen, the damage happened predominately in the form of flexural cracking of beam till the drift ratio of $2.2 \%$. Beyond this drift ratio, damage happened in the form of joint shear cracking. A delay in the joint damage was observed in the case of upgraded specimen.

\subsection{Load displacement hysteresis}

The load displacement hystereses obtained from the experiments carried out on GLD specimens of three different scenarios are presented in figures 8(a)-(c). From these figures, it could be observed that the performance of SP1-CR is the lowest with the load carrying capacity being lower than uncorroded GLD in both positive and negative cycles (in positive cycle, beam bottom has tension and in 


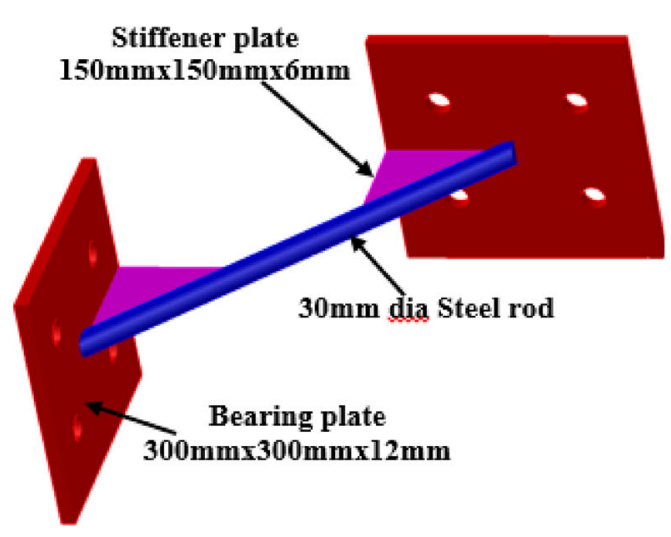

(a)

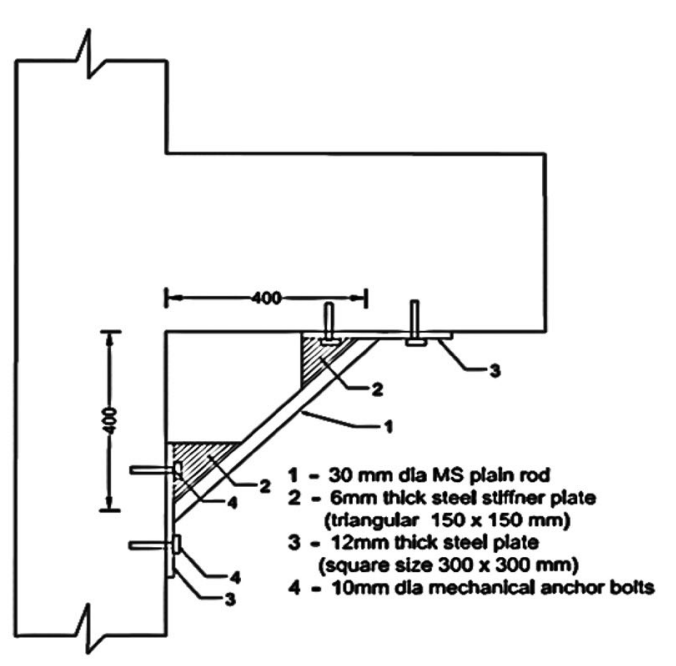

(b)

Figure 4. (a) Typical haunch unit. (b) Details of steel haunch retrofit.

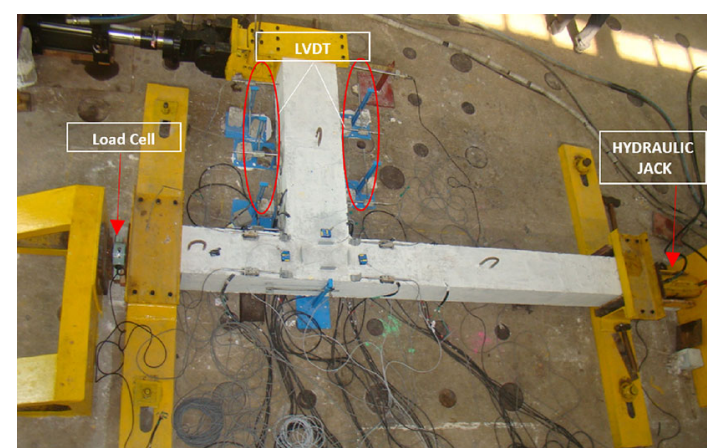

Figure 5. Specimen in test set-up along with instrumentation.

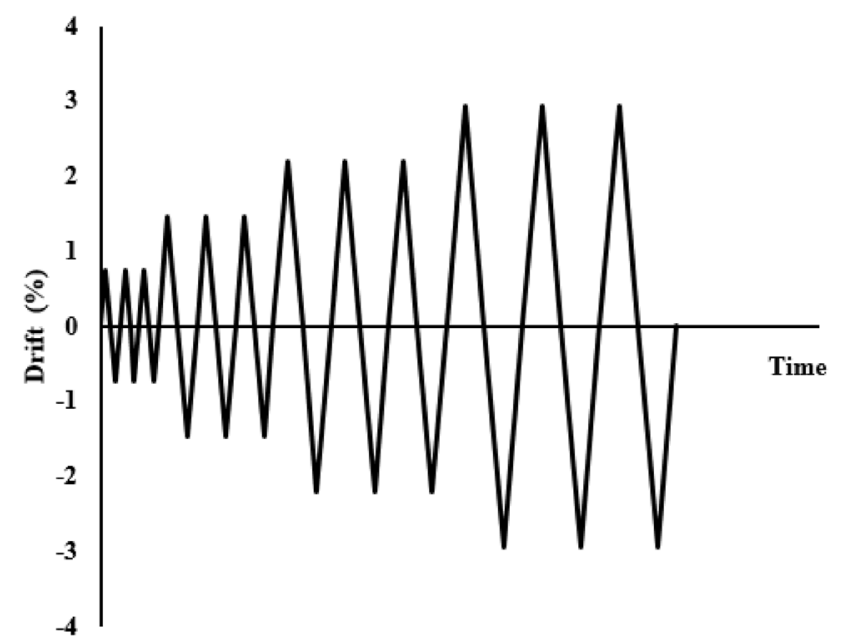

Figure 6. Displacement loading history used in the experimental investigations. negative cycle, beam top has tension). Being GLD specimen, SP1 showed poor performance by drop in load during positive cycles after drift ratio of $1.47 \%$ due to inadequate reinforcement to cater for seismic type of loading.

The presence of the single steel haunch at the bottom face of beam improved the overall load carrying capacity of the GLD specimen as shown in figure 8(c). The load carrying capacity of the SP1-U is increased in both positive and negative displacement cycles. The load carrying capacity of upgraded specimen SP1-U increased till the drift ratio $+2.20 \%(37.5 \mathrm{~mm})$ in positive cycle and $-2.94 \%(50 \mathrm{~mm})$ in the negative cycle. Figure $8(\mathrm{~d})$ depicts the performance of beam-column sub-assemblages of three different scenarios (uncorrodded GLD, corroded GLD, Upgraded uncorroded GLD) at drift ratio of $2.2 \%$ $(37.5 \mathrm{~mm})$. A remarkable improvement in the seismic performance of upgraded GLD could be observed from figure $8(d)$. Further, in order to compare maximum load carrying capacity quantitatively, the load-displacement envelopes of the SP1, SP1-CR and SP1-U are shown in figure 9 . From the load-displacement envelopes, it could be seen that the maximum load carried by SP1-CR in the positive displacement cycle decreased by $21 \%$ compared to the maximum load carried by SP1, due to the reinforcement corrosion of $5.37 \%$ at beam bottom. Corrosion of approximately $2 \%$ in the top reinforcement did not produce any significant reduction in the load carrying capacity of the member during negative displacement cycle. The upgraded specimen SP1-U exhibited impressive performance in both positive and negative cycles and the maximum load carried by SP1-U is $31 \%$ and $48 \%$ higher than SP1 in the positive and negative cycles, respectively. The maximum load carried by SP1-U at the drift ratio of $\pm 2.94 \%(50 \mathrm{~mm})$ is $136 \%$ and $126 \%$ higher than the maximum load carried by 


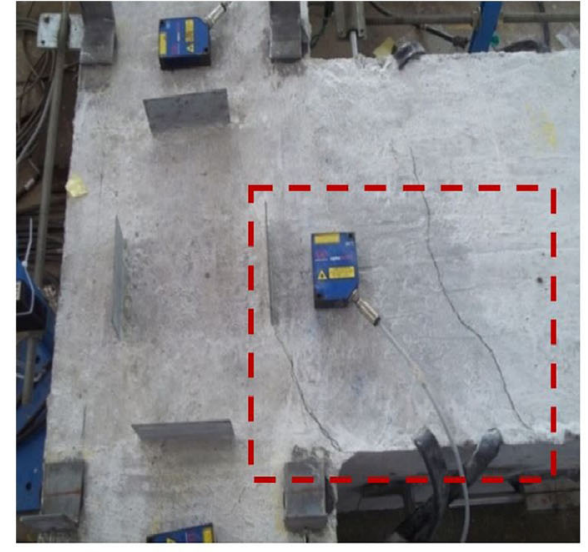

(a)

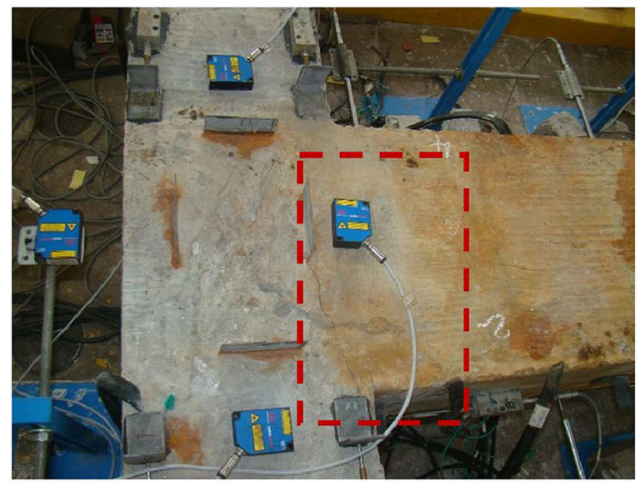

(b)

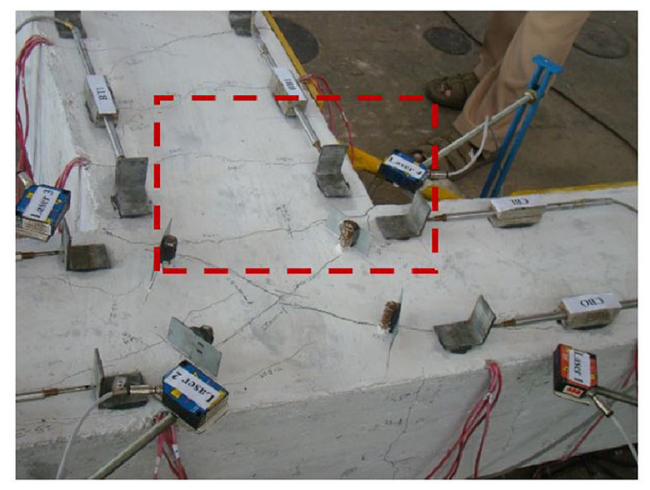

(c)
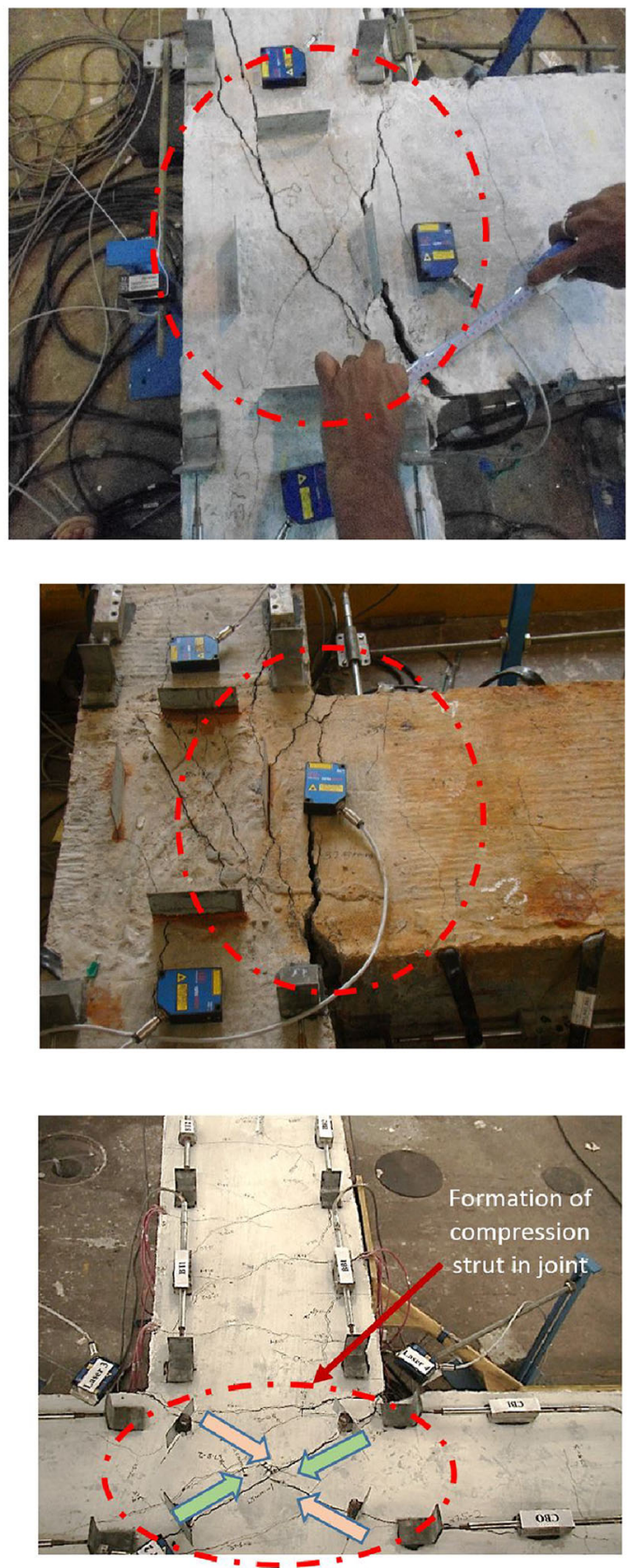

Figure 7. (a) Crack patterns observed in specimen -SP1 (initial and final crack patterns). (b) Crack patterns observed in specimen SP1-CR (initial and final crack patterns). (c) Crack patterns observed in specimen - SP1-U (initial and final crack patterns).

SP1 at the same drift ratio (figure 9). Thus, it could be concluded that the provision of single steel haunch improves the overall hysteretic behaviour of the beamcolumn sub-assemblage with improved load carrying capacity in both positive and negative displacement cycles. Further, there is delay in global strength degradation in the case of upgraded specimen SP1-U as degradation in load carrying capacity of SP1-U occurred after the drift ratio of $2.2 \%$, whereas degradation in load carrying capacity of SP1 occurred at drift ratio of $+1.47 \%$ itself.

\subsection{Energy dissipation capacity}

The energy dissipation capacity is the key performance parameter as most of the energy imparted to system during earthquake is dissipated by the joint. Energy dissipation of the specimens under cyclic loading has been calculated from the area enclosed in load-displacement hysteresis curve at each drift ratio, as shown in figure 10. The cumulative energy dissipation capacity of the specimen at any drift ratio is obtained as sum of energy dissipated by all the cycles till 


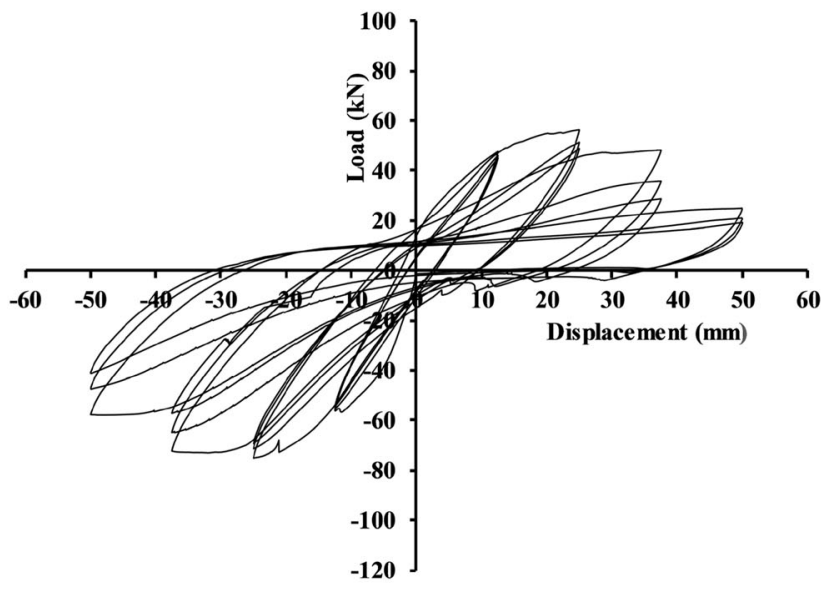

(a)

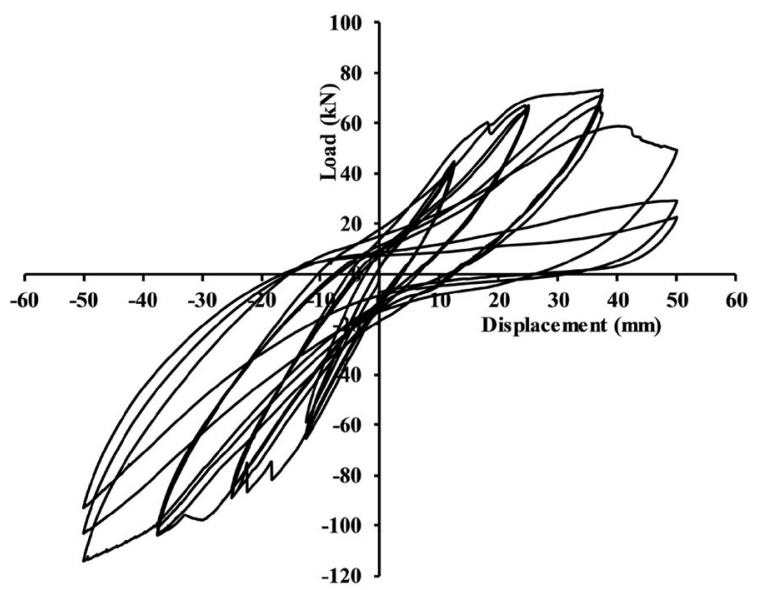

(c)

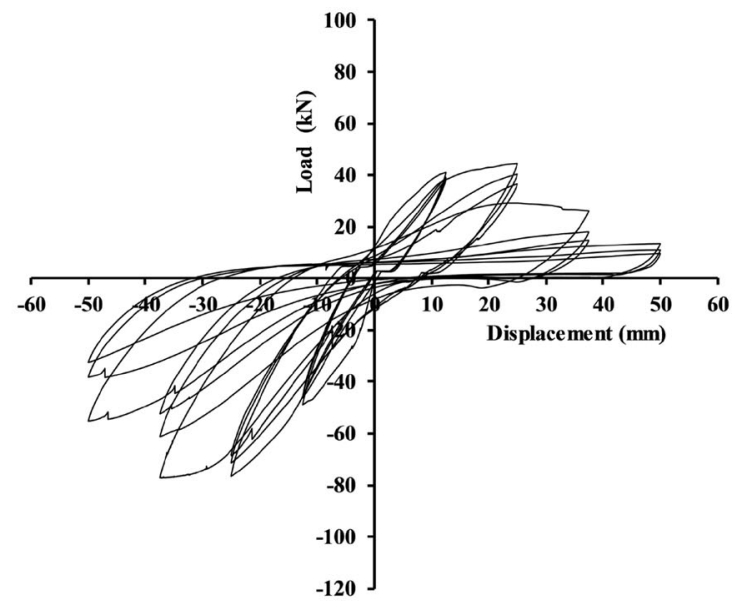

(b)

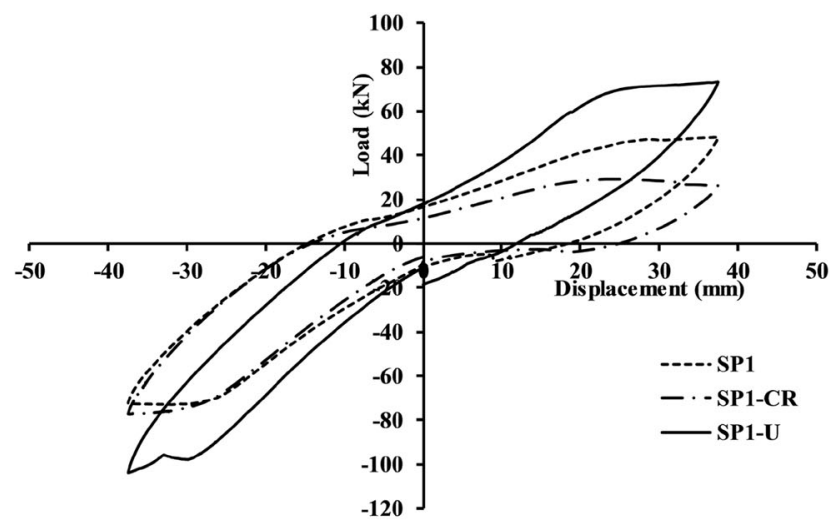

(d)

Figure 8. Load-displacement hystereses for three scenarios of GLD specimens under reverse cyclic loading. (a) Load-displacement hysteresis of SP1. (b) Load-displacement hysteresis of SP1-CR. (c) Load-displacement hysteresis of SP1-U. (d) Typical loaddisplacement hysteresis obtained for first cycle at drift ratio of $2.2 \%$ for SP1, SP1-CR and SP1-U.

that drift ratio and is shown in figure 11. Till the appearance of shear cracks at the joint, cumulative energy dissipation capacity of all the three specimens remains almost same up to drift ratio of $1.47 \%$ as shown in figure 11 . After the drift level of $1.47 \%$, there is a huge drop in the cumulative energy dissipation of SP1-CR when compared to other two specimens SP1 and SP1-U. The maximum cumulative energy dissipation capacity of the SP1-CR is $24 \%$ lower than that of the uncorroded GLD specimen SP1. Whereas the maximum cumulative energy dissipation capacity of SP1-U is $17 \%$ higher than that of SP1. Hence, it could be observed that there is remarkable improvement in the energy dissipation capacity of the upgraded specimen.
Energy dissipated in each cycle of every drift ratio is shown in figure 12. From figure 12, it may be observed that all the three specimens dissipated more energy in the first cycle of each drift ratio compared to the subsequent cycles at the same drift ratio, as shown in figure 12. It could be observed that the energy dissipated by the first cycle of each drift ratio increases with the increase in drift increment in the case of upgraded specimen which is absent in the other two specimens. The energy dissipated by SP1-CR in the first cycle at the drift ratio of $2.94 \%$ is $35 \%$ lower than that by SP1. Whereas SP1-U exhibits $49 \%$ higher energy dissipation compared to that of SP1. Thus, the upgraded specimen exhibited superior energy 


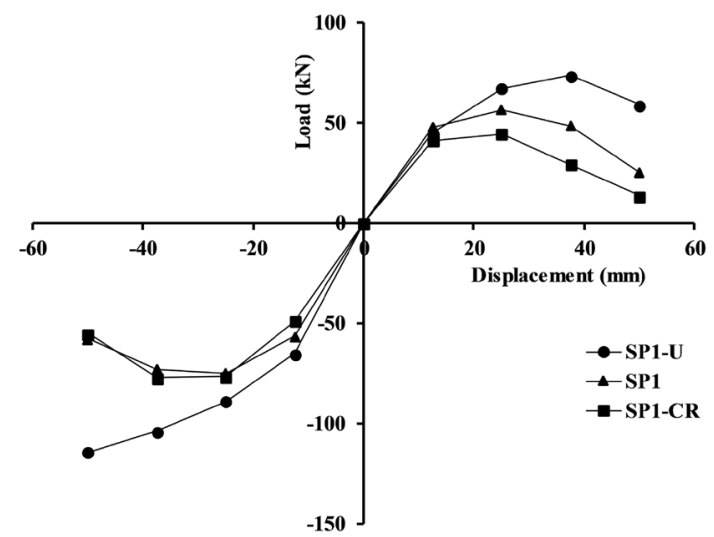

Figure 9. Load-displacement envelopes of specimens.

dissipation capacity when compared to other two specimens.

\subsection{Stiffness degradation}

The stiffness degradation is expressed as the percentage degradation in stiffness of all cycles of each drift ratio to the stiffness of first cycle of initial drift ratio. Stiffness of each cycle is calculated as the slope corresponding to maximum displacement. The stiffness degradation of all the three specimens at different drift ratios is shown in figure 13. The stiffness degradation is large in positive drift cycle for all the specimens when compared to corresponding negative drift cycles. For example, at the drift ratios of $+2.94 \%$ and $-2.94 \%$, the stiffness degradation of (i) SP1 is $86 \%$ and $74 \%$, (ii) SP1-CR is $91 \%$ and $71 \%$ and (iii) $\mathrm{SP} 1-\mathrm{U}$ is $72 \%$ and $51 \%$, respectively. At the drift ratio of $+2.94 \%$, the stiffness degradation of the first cycle of SP1-CR is $6 \%$ higher than that of SP1 whereas stiffness degradation of the SP1-U is $16.4 \%$ lesser than that of SP1. The stiffness degradation of the SP1-U is much lower than that of the SP1 as shown in figure 13. At drift ratio of $-2.94 \%$, the stiffness degradation of (i) SP1 is $74 \%$, (ii) $\mathrm{SP} 1-\mathrm{CR}$ is $71 \%$, (iii) SP1-U1 is $61 \%$. At the drift ratio of $-2.94 \%$, the stiffness degradation of specimen SP1-U is $30 \%$ smaller than that of the SP1. The SP1-U has much lower stiffness degradation in both positive and negative cycles. Thus, the upgraded specimen exhibited much lower stiffness degradation than the uncorroded GLD specimen SP1 in both positive and negative cycles, thereby demonstrating its efficacy and effectiveness.

\subsection{Strength degradation}

The strength degradation is expressed as percentage degradation in strength during second and third cycles with respect to the first cycle of each drift ratio. The strength degradation of specimens SP1, SP1-CR and SP1-U is

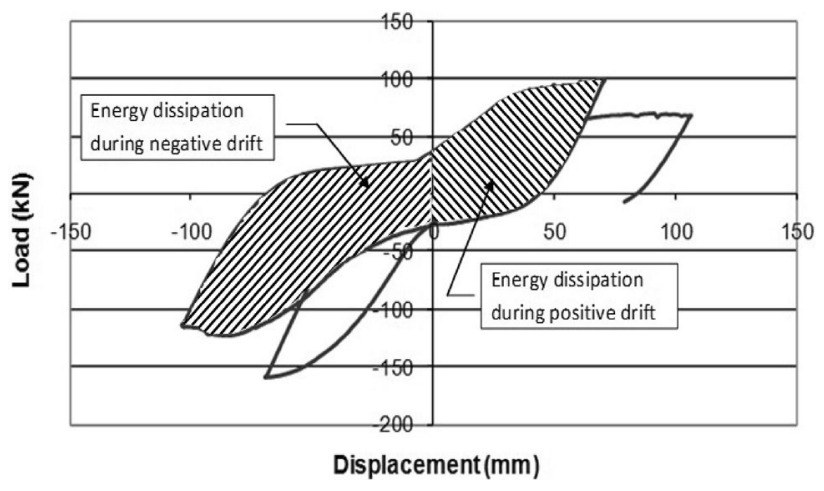

Figure 10. Calculation of energy dissipation from load-displacement hysteresis.

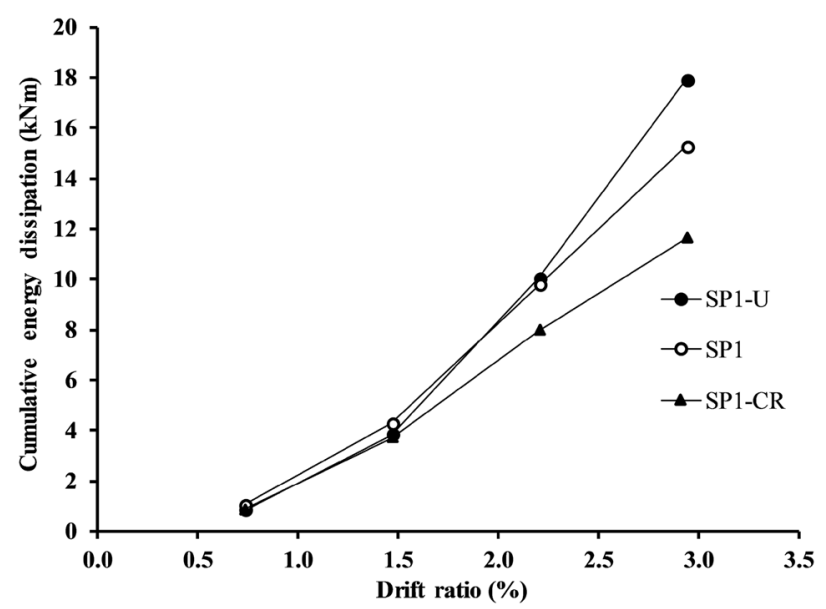

Figure 11. Cumulative energy dissipation capacity corresponding to each drift ratio.

evaluated for all the cycles at each drift ratio and is presented in figure 14. It is noted that the strength degradation of specimen SP1-CR is slightly higher than specimen SP1 as can be seen in figure 14. Also, it may be noted that the strength degradation is higher during positive drift cycles compared to negative drift cycles. The strength degradation between second and third cycles is smaller compared to the strength degradation between first and second cycles for all the three specimens. The strength degradation increases with the increase in drift ratio (both positive and negative drift ratios). At drift ratio of $+2.2 \%$, the strength degradation between first and third cycles of SP1 and SP1-CR is $40 \%$ and $49 \%$, respectively. At drift ratio of $-2.2 \%$, the strength degradation between first and third cycles of SP1 and SP1-CR is $21 \%$ and $32 \%$, respectively. Even though SP1-U showed strength degradation behaviour, the percentage degradation is less compared to that of the SP1 as can be seen in figure 14. Thus, the upgraded specimen exhibited lesser strength degradation than that of specimen SP1 and much lesser than that of SP1-CR. At the drift of $+2.94 \%$, the percentage degradation in SP1-U is very large 


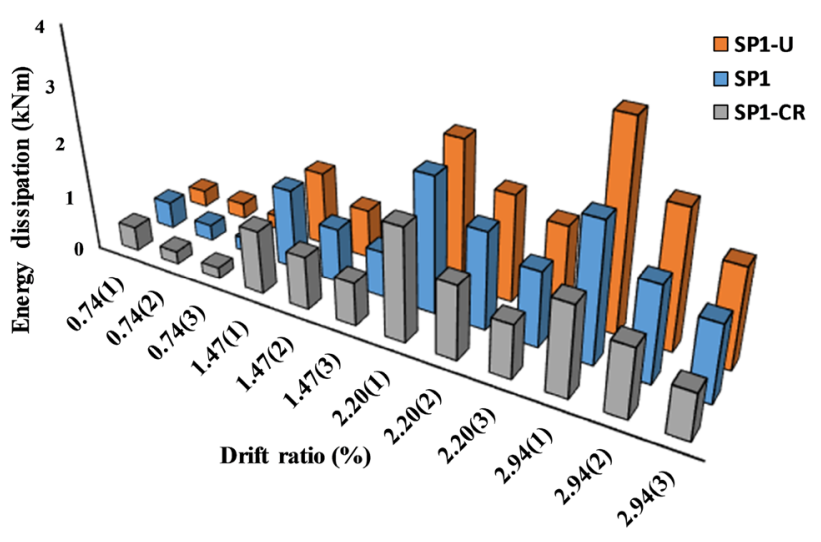

(1),(2), and(3) represents the cycle number corresponding to each drift ratio

Figure 12. Energy dissipation capacity associated with each cycle of drift ratio.

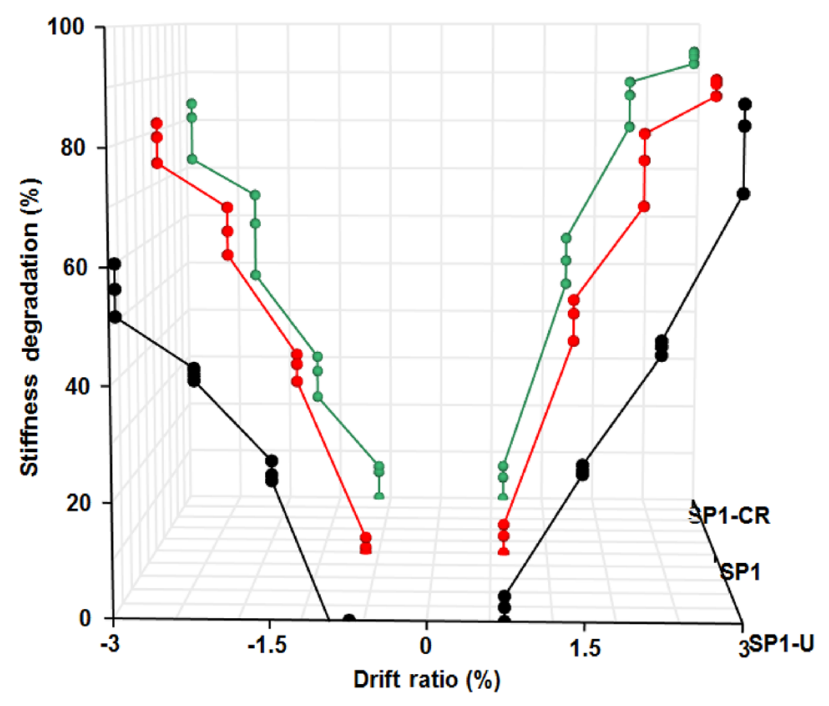

Figure 13. Stiffness degradation of the GLD specimens of different scenarios.

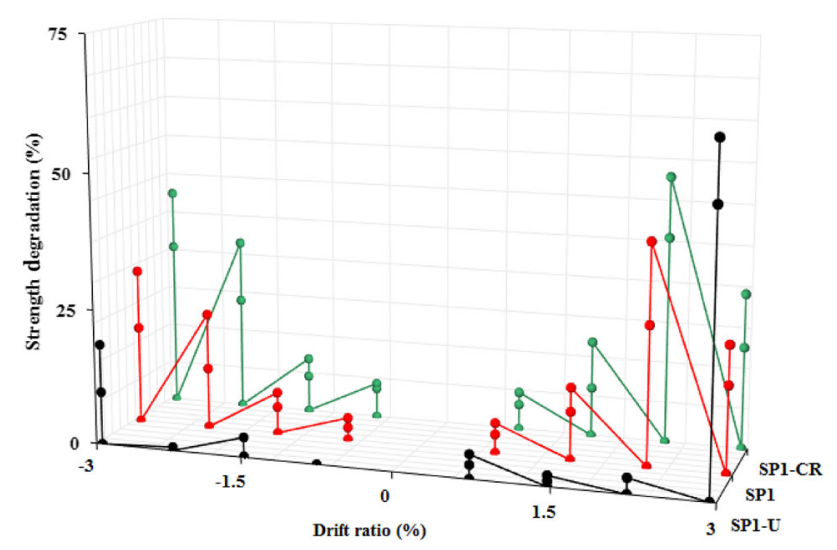

Figure 14. Strength degradation of the GLD specimens of different scenarios. when compared to other smaller drift ratios, after the pulling-off of bolts from the bottom of the beam. At $2.94 \%$, the strength degradation in SP1-U is $50 \%$ and $61 \%$ in second and third cycles, respectively.

\section{Conclusions}

Experimental investigations are carried out to assess the performance of GLD specimen subjected to reverse cyclic loading and to evaluate the degree of degradation in the performance when such specimen is corrosion affected. In the present study, the accelerated corrosion of the reinforcement is induced by impressed current technique. Further, a feasible and low-invasive single steel haunch upgradation scheme is implemented for the GLD beamcolumn sub-assemblage. The maximum load carried by SP1-CR in the positive cycle is decreased by $21 \%$ compared to that of uncorroded GLD beam-column subassemblage (SP-1). It is also observed that the corrosion has a significant effect on the energy dissipation, load carrying capacity and the strength degradation. The upgraded specimen SP1-U exhibited impressive performance and the maximum load carried by SP1-U is $31 \%$ and $48 \%$, respectively higher than that of SP1 in the positive and negative cycles, respectively. The maximum load carried by SP1-U at the drift ratios of $\pm 2.94 \%$ is $136 \%$ and $126 \%$ higher than the maximum load carried by SP1 at the same drift ratio. At the drift ratio of $2.94 \%$ the cumulative energy dissipation capacity of SP1-U is found to be $17 \%$ more compared to that of uncorroded specimen SP1. Thus, the upgraded specimen exhibited better seismic performance than uncorroded GLD specimen SP1, in terms of loaddisplacement hystereses, energy dissipation, strength and stiffness degradation. The study provides insight into the seismic performance of the beam-column sub-assemblages which are deficient (to resist seismic force) and deteriorated due to corrosion as well. Further, the efficacy and effectiveness of a low-invasive, economic and feasible upgradation scheme using single steel haunch for strengthening of the deficient structures/components in seismic prone areas is demonstrated.

\section{Acknowledgements}

This paper is being published with the kind permission of the Director, CSIR-SERC, Chennai.

\section{References}

[1] Aycardi L E, Mander J B and Reinhorn A M 1994 Seismic resistance of reinforced concrete frame structures designed only for gravity loads: Experimental performance of sub assemblages. ACI Structural Journal 91: 552-563 
[2] Bracci J M, Reinhorn A M and Mander J B 1995 Seismic resistance of reinforced concrete frame structures designed for gravity loads: performance of structural system. ACI Structural Journal 92: 597-609

[3] El-Attar A G, White R N and Gergely P 1997 Behaviour of gravity load designed reinforced concrete buildings subjected to earthquakes. ACI Structural Journal 94: 133-145

[4] Elwood K J and Moehle J P 2002 Shake table tests on the gravity load collapse of reinforced concrete frames. In: Seventh US National Conference on Earthquake Engineering, Boston, United States of America

[5] Dhakal R P, Pan T C, Irawan P, Tsai K C, Lin K C and Chen C H 2005 Experimental study on the dynamic response of gravity-designed reinforced concrete connections. Engineering Structures 27: 75-87

[6] Ramanjaneyulu K, Novák B, Sasmal S, Roehm C, Lakshmanan N and Nagesh R Iyer 2013 Seismic performance evaluation of exterior beam column sub-assemblages designed according to different codal recommendations. Structure and Infrastructure Engineering 9: 817-833

[7] Almusallam A A 2001 Effect of degree of corrosion on the properties of reinforcing steel bars. Construction Building Materials 15: 361-368

[8] Palsson R and Mirza M S 2002 Mechanical response of corroded steel reinforcement of abandoned concrete bridge. ACI Structural Journal 99: 157-162

[9] Du Y G, Clark L A and Chan A H C 2005 Residual capacity of corroded reinforcing bars. Magazine of Concrete Research 57: $135-147$

[10] Shin S, Kang I, Lee S, Lee H and Kyung J 2007 FEM analysis on the strength of $\mathrm{RC}$ members deteriorated by local part corrosion of tension main rebar. In: Proceedings of the International Conference on sustainable Building Asia. SB07 Seoul, Korea, pp. 1161-1166

[11] Cairns J, Plizzari G A, Du Y, Law D W and Franzoni C 2005 Mechanical properties of corrosion reinforcement. ACI Materials Journal 102: 256-264

[12] Apostolopoulos C A and Papadakis V G 2008 Consequences of steel corrosion on the ductility properties of reinforcement bar. Construction and Building Material 22: 2316-2324

[13] Xia J, Jin W L, Zhao Y X and Li L Y 2013 Mechanical performance of corroded steel bars in concrete. Proceedings of the Institution of Civil Engineers. Structures and Buildings 166: 235-246

[14] Fang C, Lundgren K, Plos M and Gylltoft K 2006 Bond behaviour of corroded reinforcing steel bars in concrete. Cement and Concrete Research 36:1931-1938

[15] Bhargava K, Ghosh A K, Mori Y and Ramanujam S 2007 Models for corrosion-induced bond strength degradation in reinforced concrete. ACI Materials Journal 104: 594-603
[16] Chung L, Kim J H J and Yi S T 2008 Bond strength prediction for reinforced concrete members with highly corroded reinforcing bars. Cement and Concrete Composites 30: 603-611

[17] Lee H S, Noguchi T and Tomosawa F 2002 Evaluation of the bond properties between concrete and reinforcement as a function of the degree of reinforcement corrosion. Cement and Concrete Research 32: 1313-1318

[18] Lee H S, Kage T, Noguchi T and Tomosawa F 2003 An experimental study on the retrofitting effects of reinforced concrete columns damaged by rebar corrosion strengthened with carbon fiber sheets. Cement and Concrete Research 33: $563-570$

[19] Almusallam A A, Gahtani A S, Aziz A R, Dakhil F H and Rasheeduzzafa 1996 Effect of reinforcement corrosion on flexural behavior of concrete slabs. ASCE Journal of Materials in Civil Engineering 8: 123-127

[20] Acosta A A T, Gutierreza S N and Guillenb G T 2007 Residual flexure capacity of corroded reinforced concrete beams. Engineering Structures 29: 1145-1152

[21] Realfonzo R, Napoli A and Pinilla J G R 2014 Cyclic behavior of RC beam-column joints strengthened with FRP systems. Construction and Building Materials 54: 282-297

[22] Campione G, Cavaleri L and Papia M 2015 Flexural response of external R.C. beam-column joints externally strengthened with steel cages. Engineering Structures 104: $51-64$

[23] Kalogeropoulos G I, Tsonos A D G, Konstandinidis D and Tsetines S 2016 Pre-earthquake and post-earthquake retrofitting of poorly detailed exterior RC beam-to-column joints. Engineering Structures 109: 1-15

[24] Yu Q S, Uang C M and Gross J 2000 Seismic rehabilitation design of steel moment connection with welded haunch. ASCE Journal of Structural Engineering 126: 69-78

[25] Pampanin S and Christopoulos C 2003 Non-invasive retrofit of existing RC frames designed for gravity loads only. In: Proceedings of Fibrillation Symposium 2003: Concrete Structure in Seismic Regions, Athens, Greece

[26] Pampanin S, Christopoulos C and Chen TH 2006 Development and validation of a metallic haunch seismic retrofit solution for existing under-designed RC frame buildings. Earthquake Engineering and Structural Dynamics 35: 1739-1766

[27] Genesio G, Sharma A, Eligehausen R, Pampanin S and Reddy G R 2010 Development of Seismic Retrofit technique of RC frame using fully fastened haunch elements: Static to dynamic testing. In: Proceedings of 14th Symposium on Earthquake Engineering. Roorkee. India, Paper No. A 0017 